Supporting Information

\title{
Facile Preparation of an Ether-free Anion Exchange Membrane with Pendant Cyclic Quaternary Ammonium Groups
}

Rong Ren, ${ }^{\dagger}$ Shuomeng Zhang, ${ }^{\dagger}$ Hamish Andrew Miller,,$\stackrel{*}{\star}$ Francesco Vizza, ${ }^{\dagger}$ John Robert Varcoe, ${ }^{*} \S$ Qinggang $\mathrm{He}^{*}, \grave{\dagger}, \|$

$\dagger$ College of Chemical and Biological Engineering, Zhejiang University, Hangzhou, Zhejiang 310027, China

Institute of Chemistry of Organometallic Compounds, ICCOM-CNR, Polo Scientifico Area CNR, 50019 Sesto Fiorentino, Italy

§Department of Chemistry, the University of Surrey, Guildford, Surrey GU2 7XH, UK

"Ningbo Research Institute, Zhejiang University, Ningbo, Zhejiang 315100, China

E-mail: *qghe@zju.edu.cn (Q. He), *hamish.miller@iccom.cnr.it (H. A. Miller), *j.varcoe@surrey.ac.uk (J. R. Varcoe) 


\section{Experimental}

Instrumentation

${ }^{1} \mathrm{H}$ NMR spectra were obtained with a Bruker $400 \mathrm{MHz}$ spectrometer, and chemical shifts were referenced to the residue solvent peaks; $\mathrm{CDCl}_{3}$ (at $7.26 \mathrm{ppm}$ ) and DMSO- $d_{6}$ (at $2.50 \mathrm{ppm}$ ). Number and weight average molecular weights of polymers were determined by gel permeation chromatography (GPC) on a Viscotek T60A instrument, using THF as eluent and polystyrene as standard. Thermal gravimetric analysis (TGA) data were obtained from TA Q50 instrument under nitrogen atmosphere. Small-angle X-ray scattering (SAXS) spectra were recorded in reflection mode at room temperature using a XEUSS SAXS/WAXS System (France). Atomic force microscopy (AFM) observations were performed with Agilent Keysight 5500. The mechanical properties were investigated by testing the tensile strength using Zwick/Roell Z020 with a tensile rate of $1 \mathrm{~mm} \mathrm{~min}^{-1}$ at $30 \%$ relative humidity (RH).

\section{Materials}

Fluorene, 1,6-dibromohexane, 1,1,1-trifluoroacetone, tetrabutylammonium iodide, biphenyl, trifluoromethanesulfonic acid were purchased from J\&K company. All other inorganic salts and solvents were supplied by Shanghai Sinopharm Chemical Reagent Co., Ltd. (China) and used without further purification.

Synthesis of 9,9-Bis-(6-bromohexyl)-9H-fluorene (BHF) 
BHF was prepared by the alkylation of fluorene via direct $\mathrm{C}-\mathrm{H}$ alkylation under aqueous conditions according to a synthesis route reported elsewhere. ${ }^{1}$ Fluorene $(3.3$ g, $20 \mathrm{mmol}), 15 \mathrm{~mL}$ aqueous $\mathrm{NaOH}(50 \mathrm{wt} \%)$, 1,6-dibromohexane (34 g, $0.14 \mathrm{~mol})$ and a catalytic amount of tetrabutylammonium iodide $(0.74 \mathrm{~g}, 10 \mathrm{~mol} \%)$ were added to a flask. The flask was degassed three times by applying freeze-thaw cycles. The reaction mixture was then heated at $70{ }^{\circ} \mathrm{C}$ continuously for $4 \mathrm{~h}$, then cooled to room temperature and extracted with chloroform. The organic layer was washed with water and dried over anhydrous sodium sulfate. The solvent was removed under vacuum, and the crude product was purified via column chromatography with $10 \%$ chloroform in hexane as the eluent to obtain the desired product.

Synthesis of PF homopolymer

A mixture of BHF (1.48g, $3.00 \mathrm{mmol}), 1,1,1$-trifluoroacetone $(0.37 \mathrm{~g}, 3.30 \mathrm{mmol})$, methylene chloride $(3.0 \mathrm{~mL})$, trifluoromethanesulfonic acid (TFSA) $(3.0 \mathrm{~mL})$ was stirred at room temperature under nitrogen. After $2 \mathrm{~h}$, the reaction mixture solution became highly viscous and stirring was continued for an additional $2 \mathrm{~h}$. The resulting dark-brown, gel-like mass was then diluted with $3.0 \mathrm{~mL} \mathrm{CH}_{2} \mathrm{Cl}_{2}$ before being poured slowly into methanol. A white fibrous solid was formed and was filtered and washed with hot methanol. After drying under vacuum, $1.67 \mathrm{~g}$ of white fiber-like solid was obtained (94\% yield).

Synthesis of PBF copolymers 
PBF0.5, PBF1 and PBF2 (the number corresponds to the mole ratio of BHF to biphenyl) copolymers were prepared via one-pot, acid-catalyzed Friedel-Crafts polycondensation. A typical synthetic procedure for the preparation of PBF1 is described as an example. A mixture of BHF $(0.74 \mathrm{~g}, 1.50 \mathrm{mmol})$, biphenyl $(0.23 \mathrm{~g}$, $1.50 \mathrm{mmol}), 1,1,1$-trifluoroacetone $(0.37 \mathrm{~g}, 3.30 \mathrm{mmol})$, methylene chloride $(3.0 \mathrm{~mL})$, trifluoromethanesulfonic acid (TFSA) $(3.0 \mathrm{~mL})$ was stirred at room temperature under nitrogen. After 2 hours, the reaction mixture solution became highly viscous and stirring was continued for additional 2 hours. The resulting dark-brown, gel-like mass was then diluted with $3.0 \mathrm{~mL} \mathrm{CH}_{2} \mathrm{Cl}_{2}$ before being poured slowly into methanol. A white fibrous solid was formed and was filtered and washed with hot methanol. After drying under vacuum, $1.06 \mathrm{~g}$ of a white fiber-like solid was obtained ( $95 \%$ yield).

Synthesis of quaternary ammonium-functionalized PBF-Br

1-Methylpiperidine was selected as the functional agent for the quarternization of the PBF and the synthesis procedure for PBF1-Br is given here. PBF1 $(0.3 \mathrm{~g})$ was dissolved in N-methyl pyrrolidone (NMP) $(6 \mathrm{~mL})$ at $25{ }^{\circ} \mathrm{C}$, then, $\mathrm{N}$-methyl piperidine $(1.0 \mathrm{~mL})$ was added. The reaction was terminated after stirring the reaction mixture at $50{ }^{\circ} \mathrm{C}$ for $12 \mathrm{~h}$. Then, the solution was diluted with $6 \mathrm{~mL}$ methanol and precipitated in anhydrous ether. The precipitate was washed several times to obtain pure functionalized copolymers. Subsequently, the product was dried at $60{ }^{\circ} \mathrm{C}$ under vacuum for $24 \mathrm{~h}$ to yield $\mathrm{PBF} 1-\mathrm{Br}(95 \%$ yield $)$. 
Membrane casting of ion-functionalized polymers

AEMs were prepared by dissolving the above QAs polymers $\left(0.5 \mathrm{~g}\right.$ in $\mathrm{Br}^{-}$anion form) in NMP $(5 \mathrm{wt} \%)$ followed by casting on a glass plate $(0.1 \mathrm{~m} \times 0.1 \mathrm{~m})$. The AEMs with thickness of $\sim 50$ um were formed after dring at $60{ }^{\circ} \mathrm{C}$ under a positive flow of air for $24 \mathrm{~h}$ and under vacuum for $24 \mathrm{~h}$.

Ion exchange of polymers to hydroxide anion form

In an Ar-filled glovebox, AEM samples $\left(\mathrm{Br}^{-}\right)$were soaked in an aqueous $\mathrm{NaOH}(1$ M) solution for $48 \mathrm{~h}$ followed by thorough washing with degassed deionized water until the $\mathrm{pH}$ became neutral. The use of degassed deionized water is imperative to avoid dissolved $\mathrm{CO}_{2}$ in air and prevent undesirable bicarbonate and carbonate formation in AEMs (rather than the desired $\mathrm{OH}^{-}$).

Ion Exchange Capacity (IEC) and Water Uptake

The IECs of AEMs in $\left(\mathrm{Cl}^{-}\right.$anion form) were determined by Mohr titration. About $0.15 \mathrm{~g}$ of AEM samples were ion exchanged in aqueous $\mathrm{KCl}(1 \mathrm{M})$ solution for $24 \mathrm{~h}$ (the $\mathrm{KCl}$ solution was changed three times during this period) and then washed with deionized water thoroughly. Each AEM sample was dried at $50{ }^{\circ} \mathrm{C}$ in vacuum for $24 \mathrm{~h}$ and weighed. Then each AEM sample ( $\mathrm{Cl}^{-}$form) was immersed in $50 \mathrm{~mL}$ of aqueous $\mathrm{NaNO}_{3}(0.2 \mathrm{M})$ solution for $8 \mathrm{~h}$ (three replacements of solution). The combined $\mathrm{NaNO}_{3}$ solution was titrated with aqueous $\mathrm{AgNO}_{3}(0.1 \mathrm{M})$ solution using $\mathrm{K}_{2} \mathrm{CrO}_{4}$ as a 
colorimetric indicator. IEC was calculated from dry mass of the membrane and the amount $\mathrm{AgNO}_{3}$ consumed in titration (1:1 precipitation titration).

In an argon-filled glovebox, fully hydrated AEM (both $\mathrm{Br}^{-}$and $\mathrm{OH}^{-}$form) samples were taken out of water, blotted quickly with a KimWipe to remove surface liquid, and weighed immediately. The membranes were then dried at $50{ }^{\circ} \mathrm{C}$ under vacuum for $24 \mathrm{~h}$ and weighed again. Water uptake (\%) was calculated from:

$$
\text { Water uptake }(\%)=\left[\left(\mathrm{W}_{\text {wet }}-\mathrm{W}_{\text {dry }}\right) \times 100\right] / \mathrm{W}_{\text {dry }}
$$

where $\mathrm{W}_{\text {wet }}$ and $\mathrm{W}_{\text {dry }}$ are the weight of the hydrated and the corresponding dry membrane samples, respectively.

Ion Conductivity Measurement

Ion conductivities $(\sigma$ in $\mathrm{mS} / \mathrm{cm})$ of $\mathrm{OH}^{-}$and $\mathrm{Br}^{-}$form $\mathrm{AEM}(\mathrm{ca} .4 \mathrm{~cm} \times 1 \mathrm{~cm})$ were measured by a four-point probe electrode method and calculated according to

$$
\sigma(\mathrm{mS} / \mathrm{cm})=\mathrm{L} /(\mathrm{RWT})
$$

where $\mathrm{L}$ is the distance between the two inner Pt potential sense wires $(1 \mathrm{~cm}), \mathrm{R}$ is the measured resistance $(\mathrm{m} \Omega)$, and $\mathrm{W}$ and $\mathrm{T}$ are the width and the thickness of the AEM sample $(\mathrm{cm})$, respectively. R was measured using four-point probe alternating current (ac) impedance spectroscopy (frequency range of $1-10^{5} \mathrm{~Hz}$ with $0.1 \mathrm{~mA}$ amplitude) under fully hydrated conditions (in water) at different temperatures. Before measurement, the AEM samples were sandwiched between two parts of a homemade Teflon cell (Figure S11). The cell was placed in a thermo-controlled chamber in 
degassed deionized water for measurement. At a given temperature, each sample was equilibrated for least $30 \mathrm{~min}$ before the impedance measurement was recorded.

Morphology Study with SAXS and AFM

The SAXS was conducted at $50 \mathrm{kV}$ and $0.6 \mathrm{~mA}$ using a wavelength of $0.154 \mathrm{~nm}$ as X-ray radiation source. Scattering data were recorded by a semiconductor detector (Pilatus 100K, DECTRIS, Switzerland). Each SAXS pattern was collected within 30 min, background correctedand normalized using the standard procedure. AEM sample was folded several times to increase the effect thickness ( $400 \mathrm{um})$. The d-spacing of the AEMs was calculated from the Bragg's law: $d=2 \pi / q$.

Tapping mode AFM observations were performed with a Keysight 5500 instrument, using microfabricated cantilevers with a force constant of approximately $20 \mathrm{~N} \mathrm{~m}^{-1}$. All AEM samples ( $\mathrm{Br}^{-}$form) were measured under ambient conditions $\left(25^{\circ} \mathrm{C}, 50 \%\right.$ $\mathrm{RH})$.

Fuel cell performance testing

Fuel cell performance on a sample of the PBF1-OH AEM was characterized in a single test cell. For MEA preparation, an AEI powder ionomer $($ IEC $=1.26 \pm 0.06$ mequiv $\mathrm{g}^{-1}$ ) was used, which was synthesized via the radiation-grafting of vinylbenzyl chloride onto an ETFE powder (Fluon Z8820X, supplied by AGC Europe) with subsequent amination using trimethylamine as described previously. ${ }^{2}$ For the cathode electrode GDE, Pt/C (Alfa Aesar, Johnson Matthey HiSpec 4000, 40\% wt Pt) 
and AEI powder $(20 \%$ wt. of the total solid mass) were mixed together with $1 \mathrm{~mL}$ water and $9 \mathrm{~mL}$ 2-propanol. The cathode catalyst ink was then homogenized with ultrasound for $30 \mathrm{~min}$, sprayed onto a Toray TGP-H-60 carbon paper gas diffusion substrate (Alfa Aesar, non-teflonated), and dried in air. For the anode GDEs, the $\mathrm{PtRu} / \mathrm{C}$ was used as catalyst (with $20 \%$ wt AEI). The $5 \mathrm{~cm}^{2}$ GDEs were loaded with $0.40 \pm 0.02 \mathrm{mg}_{\mathrm{PtRu}} \mathrm{cm}^{-2}$ and $0.40 \pm 0.02 \mathrm{mg}_{\mathrm{Pt}} \mathrm{cm}^{-2}$ for anode and cathode electrodes, respectively. All electrodes and the PBF1-OH AEM were immersed in aqueous $\mathrm{KOH}$ solution (1 M) for $1 \mathrm{~h}$ and then washed thoroughly in water (to remove excess $\mathrm{KOH}$ ) before assembly into a $5 \mathrm{~cm}^{2}$ fuel cell fixture (Scribner Associates, USA) using $5 \mathrm{~N} \mathrm{~m}$ torque.

Fuel cell performance data collection

An 850e fuel cell test station (Scribner Associates, USA) was used for testing. The fuel cell temperature was kept at $60{ }^{\circ} \mathrm{C} . \mathrm{H}_{2}$ and $\mathrm{O}_{2}$ gas feeds with flow rates of $1 \mathrm{~L}$ $\min ^{-1}$ were supplied to the anode and the cathode, respectively, at $\mathrm{RH}=75 \%$ with no back-pressurization. The MEAs were activated by discharging the cell at a constant voltage of $0.5 \mathrm{~V}$ during cell heating, until a steady current density was observed. Beginning-of-life AEMFC performance data were collected by running cell voltage potential scans from OCV to $0.3 \mathrm{~V}$ at $10 \mathrm{mV} \mathrm{s}^{-1}$. 


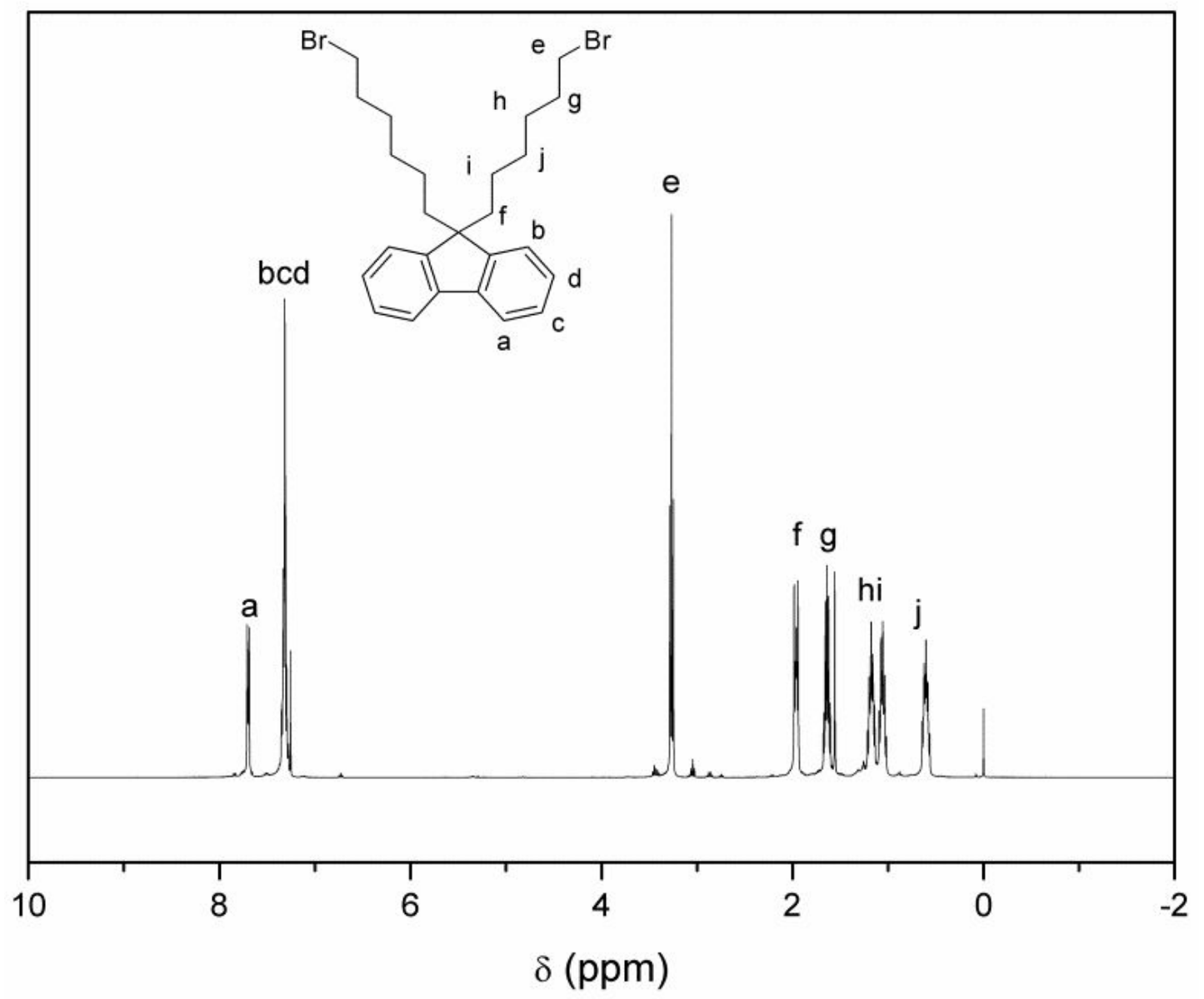

Figure S1. ${ }^{1} \mathrm{H}$ NMR spectrum of 9,9-bis-(6-bromohexyl)-9H-fluorene (BHF) 

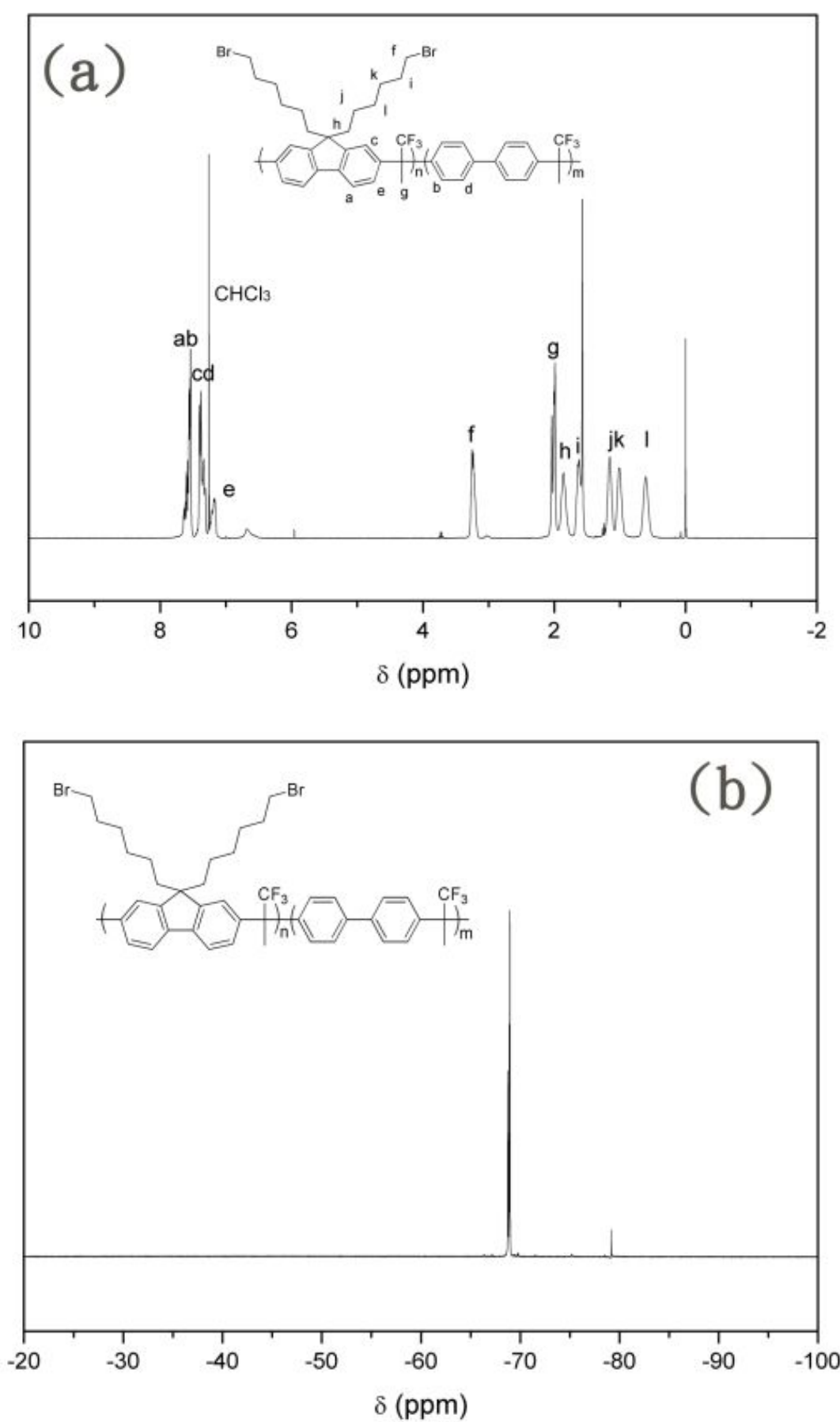

Figure S2. NMR spectra of PBF1, (a) ${ }^{1} \mathrm{H}$ and (b) ${ }^{19} \mathrm{~F}$, the minor peak at $-79 \mathrm{ppm}$ is the $-\mathrm{CF}_{3}$ at the terminal of the polymer 
(a)

(b)
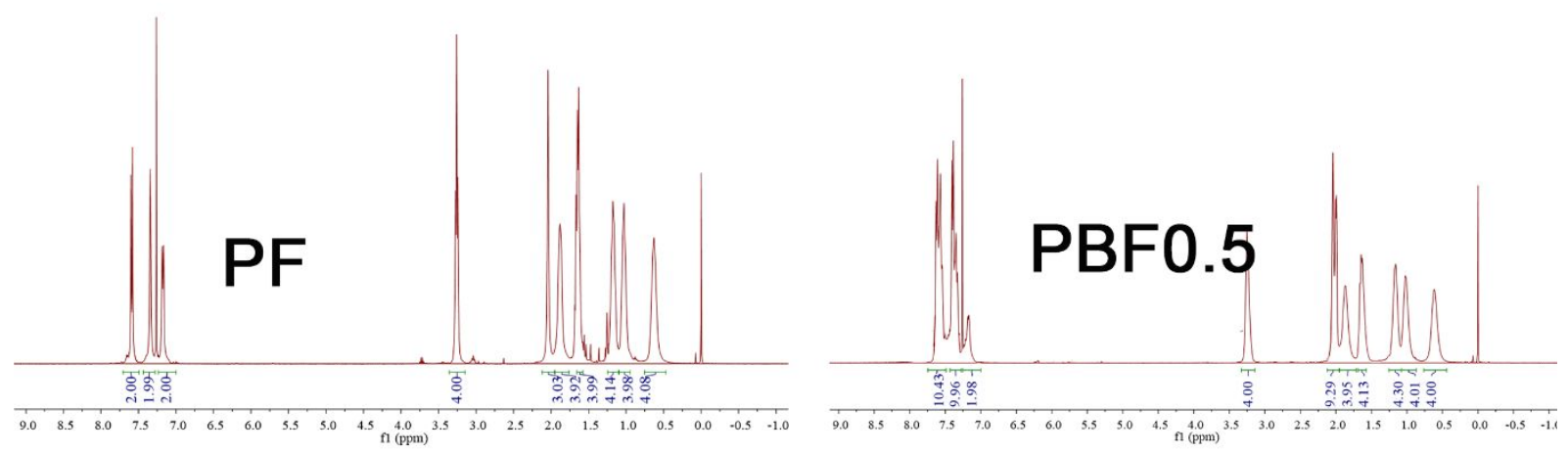

(c)

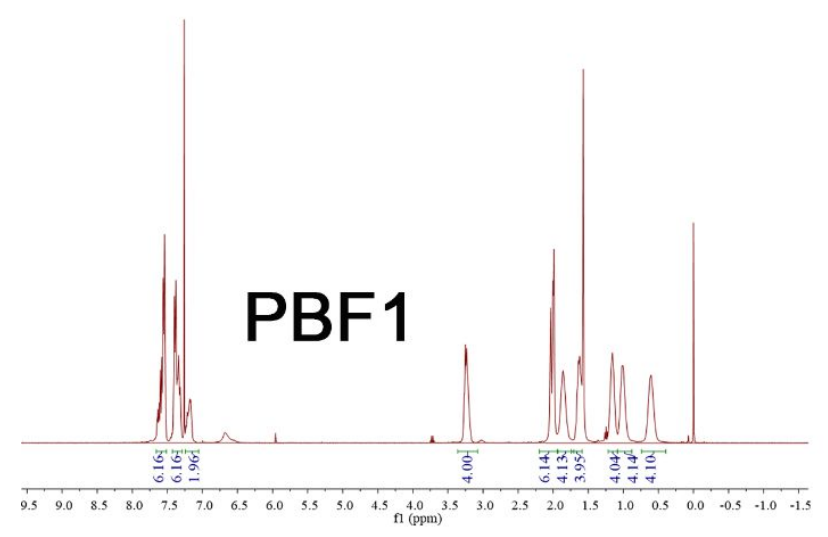

(d)

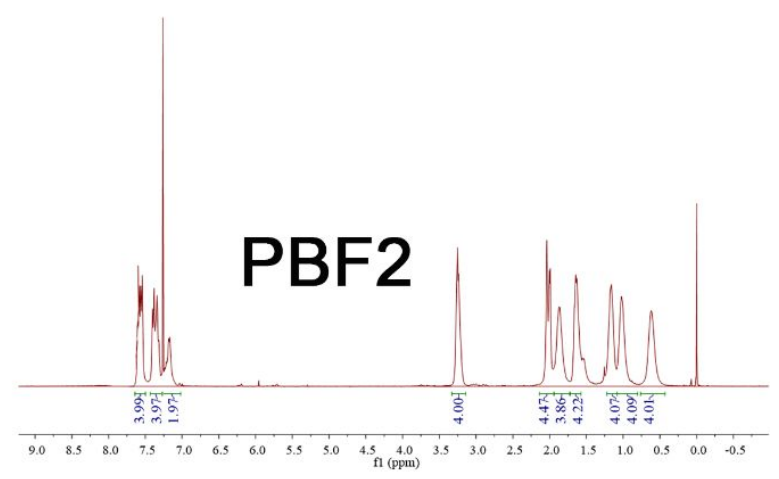

Figure S3. ${ }^{1} \mathrm{H}$ NMR spectra of PF (a) and PBF samples (b, c, d), the ratios of the two different repeating units of copolymers were calculated by the integral ratio of 3.25 ppm $\left(-\mathrm{CH}_{2} \mathrm{Br}\right)$ and $2.0 \mathrm{ppm}\left(-\mathrm{CH}_{3}\right.$ connecting the backbone) 


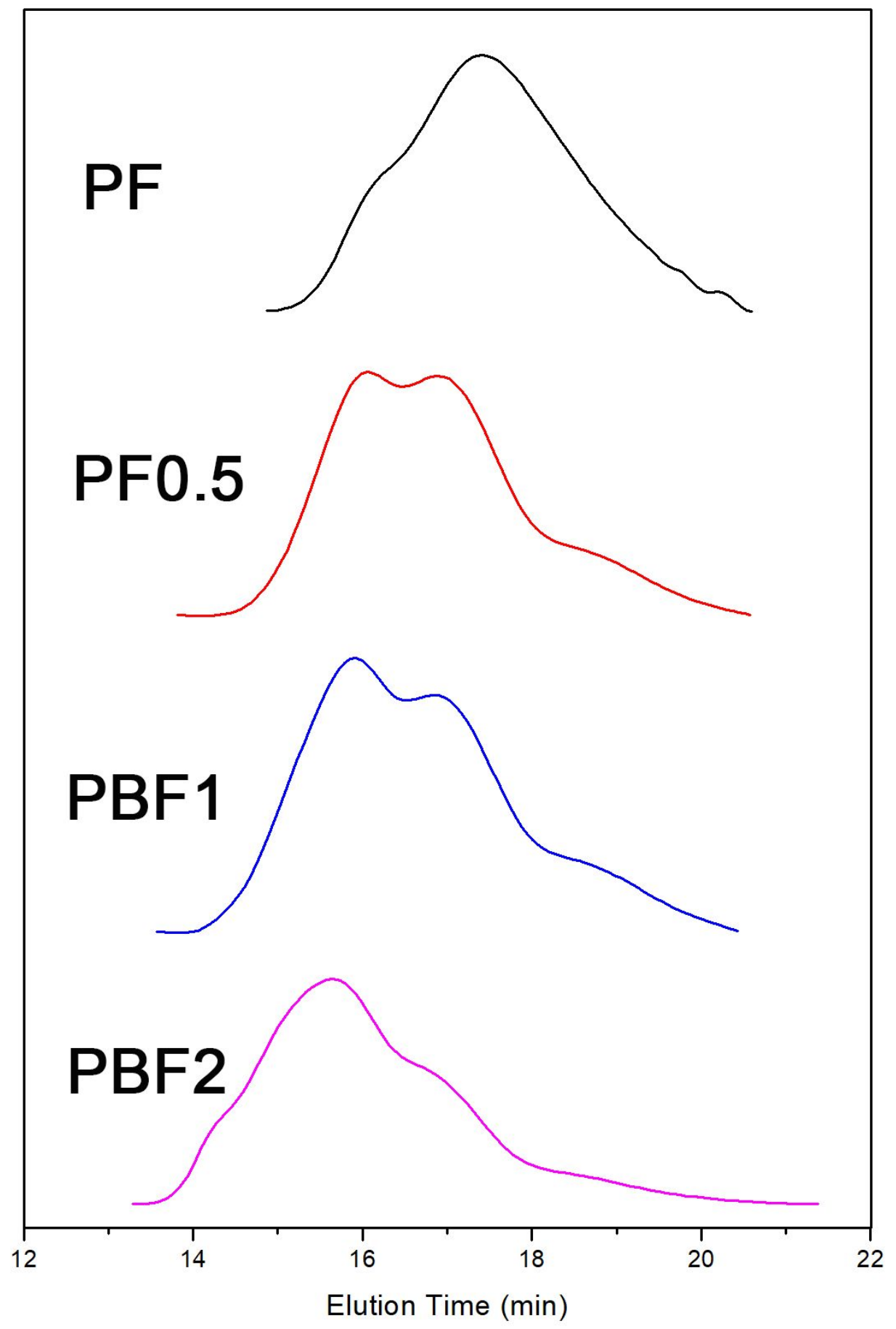

Figure S4. GPC curves of PF and PBF measured by THF with the RI detector, calibrated with linear polystyrene standards 


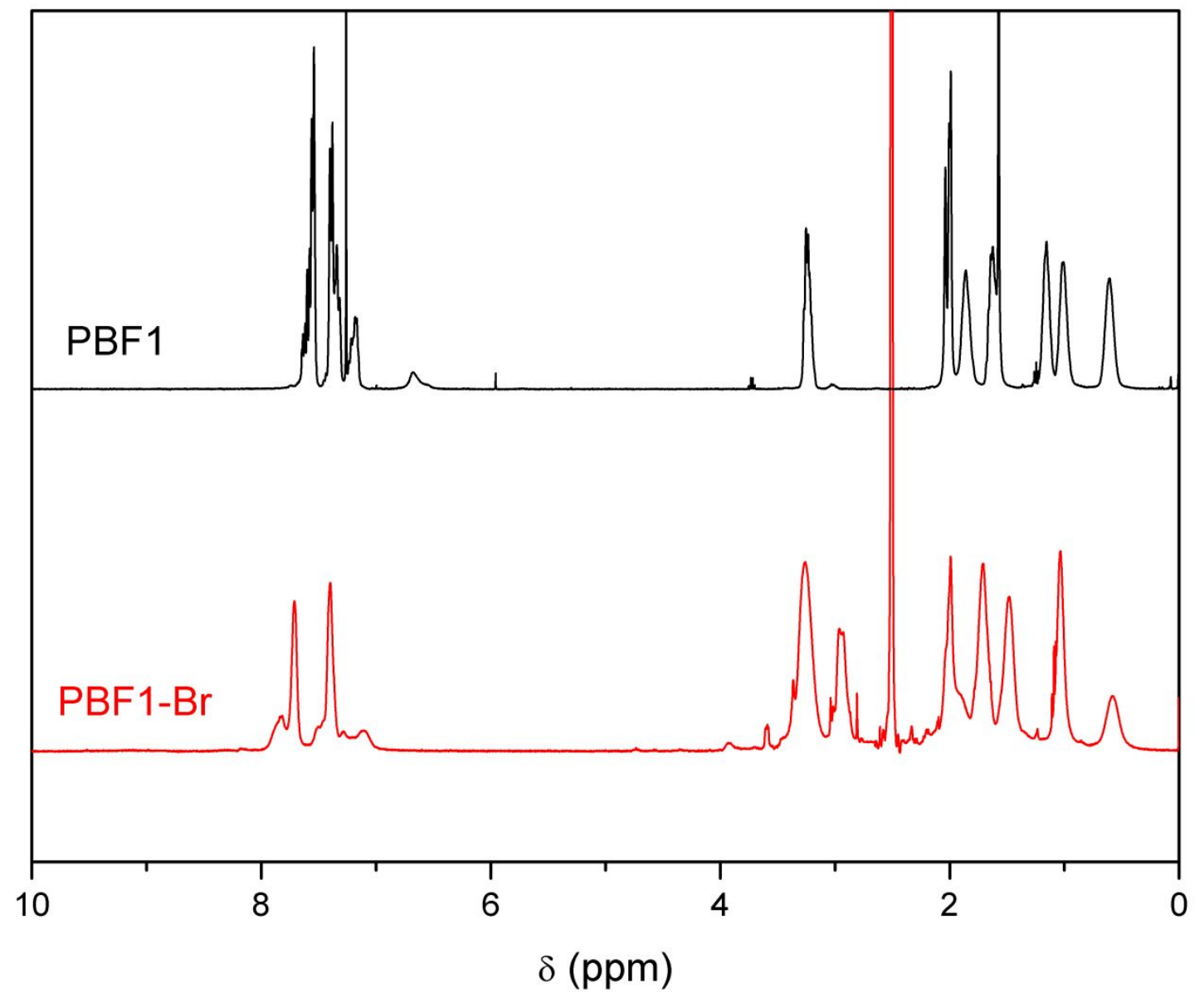

Figure S5. ${ }^{1} \mathrm{H}$ NMR spectra of PBF1 and PBF1-Br 


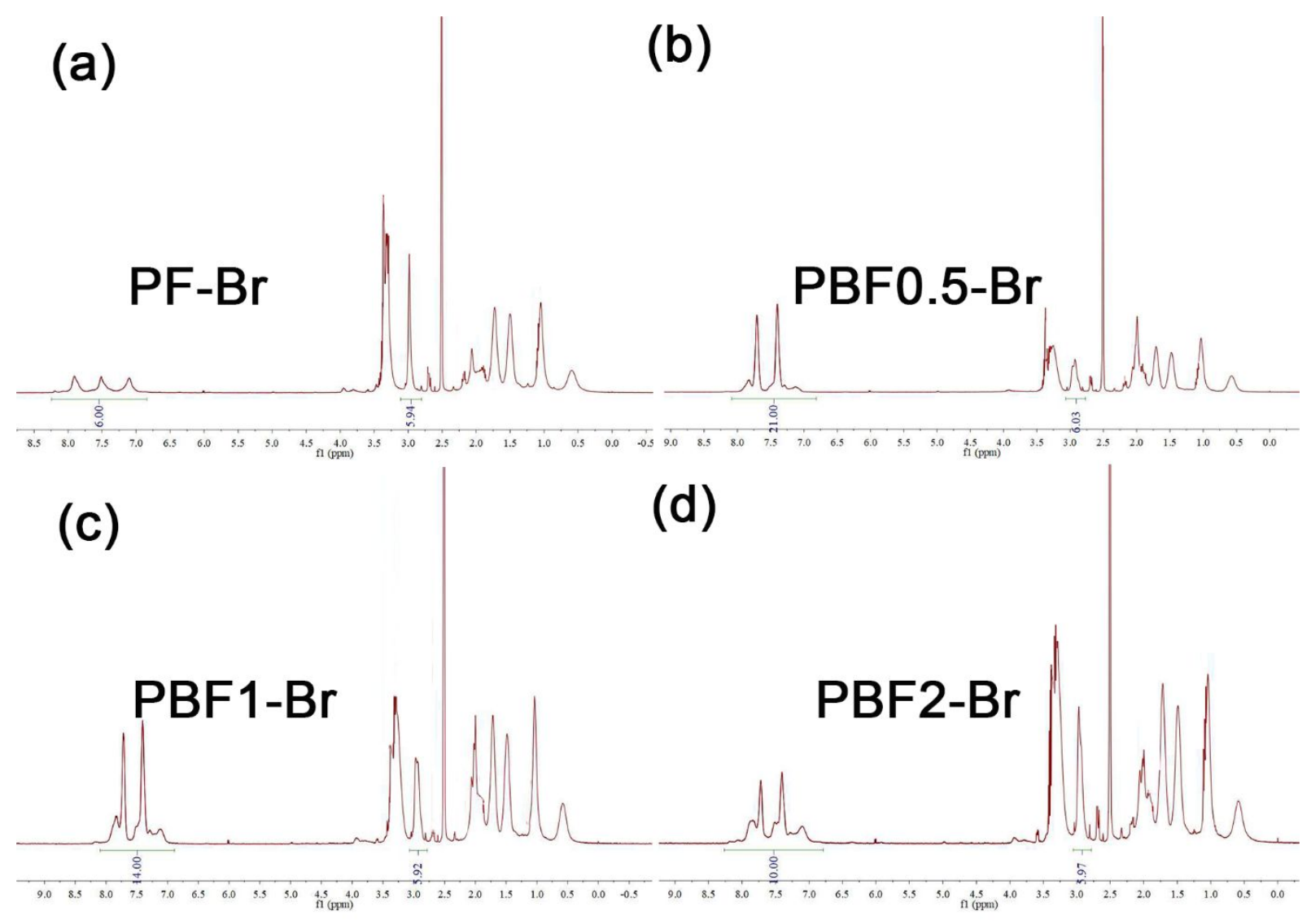

Figure S6. ${ }^{1} \mathrm{H}$ NMR spectra of PF-Br (a), PBF0.5-Br (b), PBF1-Br (c) and PBF2-Br (d) the efficiency of quarternization was calculated from the integral ratio of the QA methyl protons (2.9 ppm) and the aromatic proton peaks (7-8 ppm) 

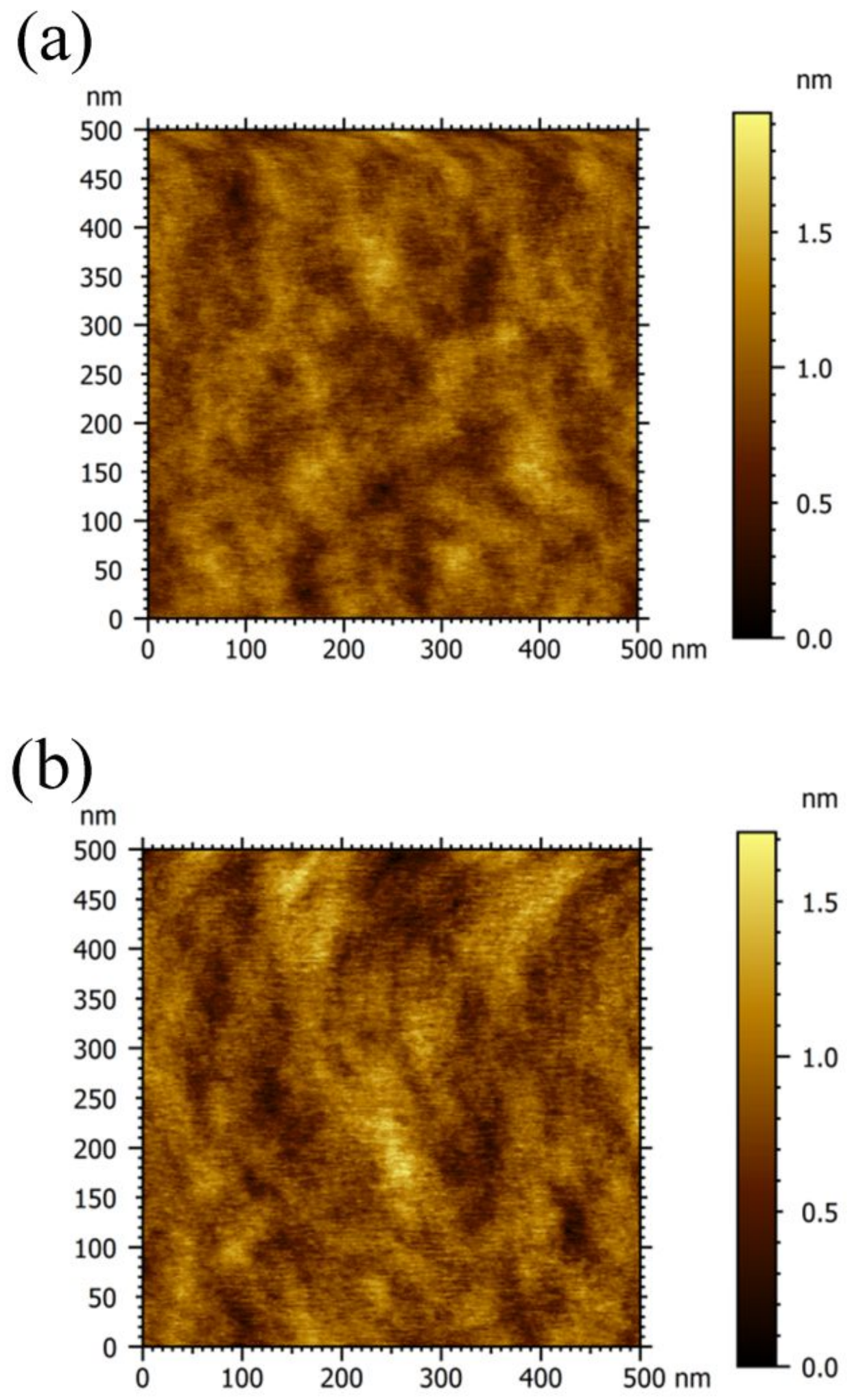

Figure S7. AFM topographical height images of PBF0.5-Br (a) and PBF2-Br (b) 

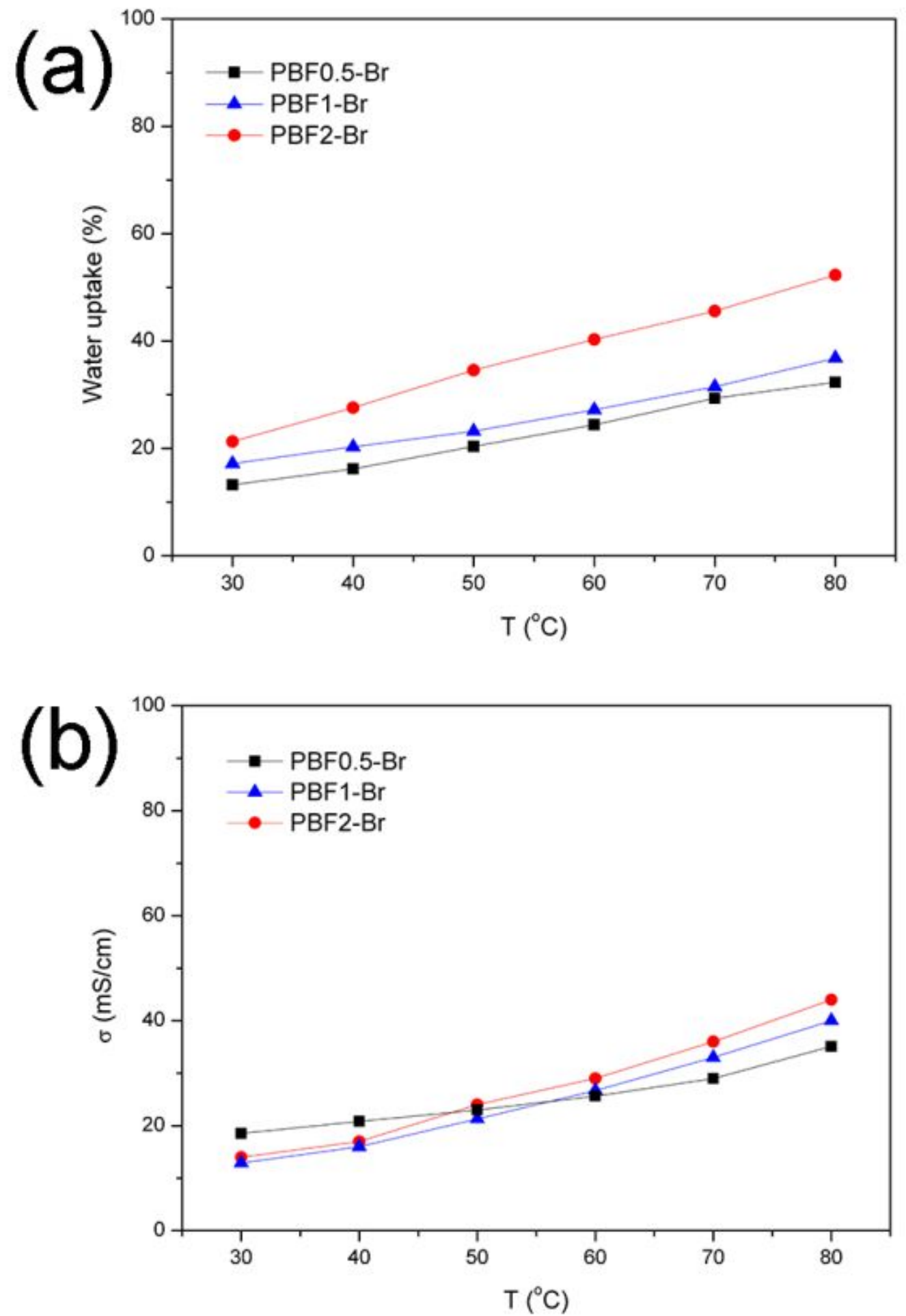

Figure S8. (a) Water uptake and (b) ionic conductivity of the PBF-Br membranes as a function of temperature 


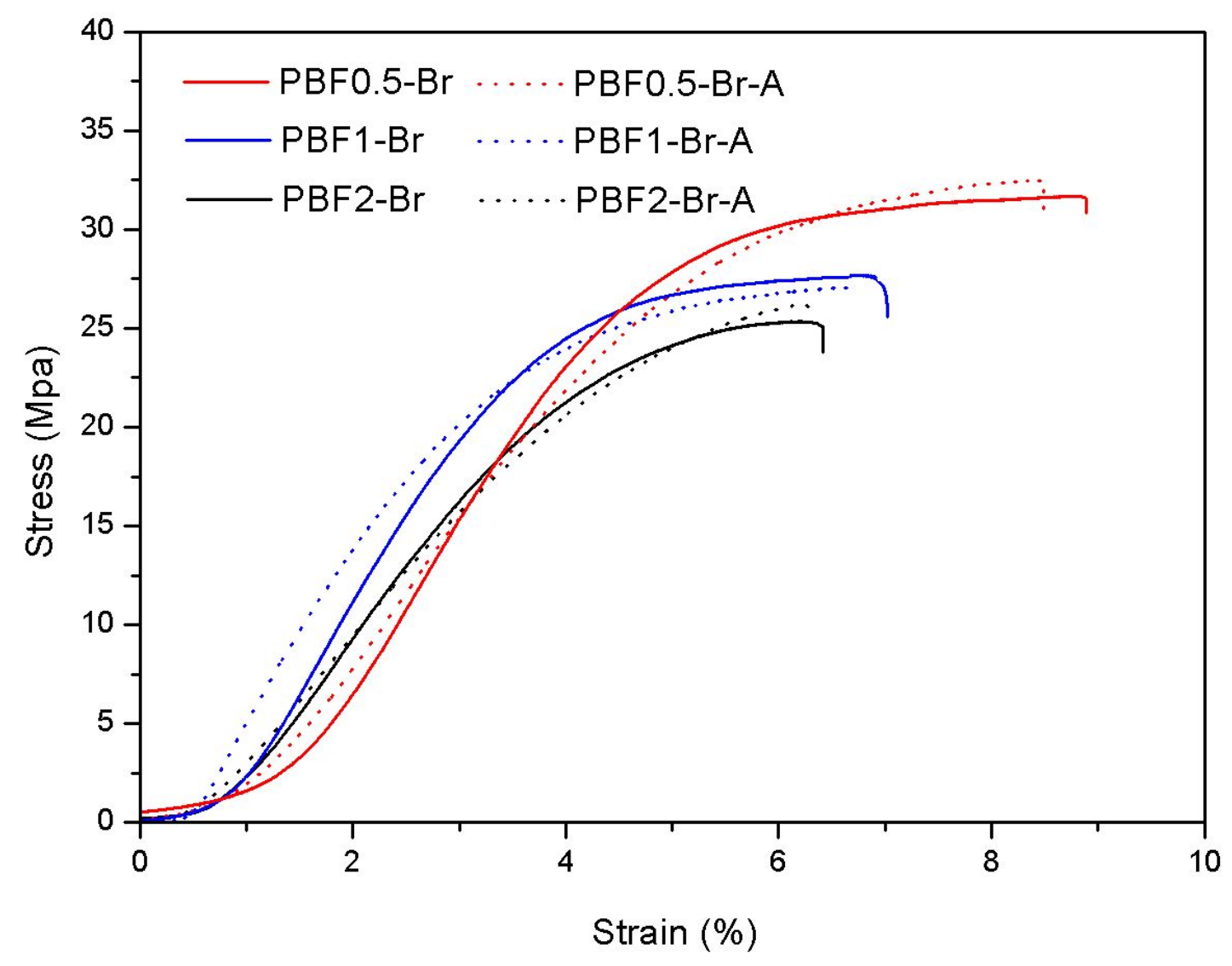

Figure S9. mechanical properties of PBF AEMs before and after alkaline treatment. 


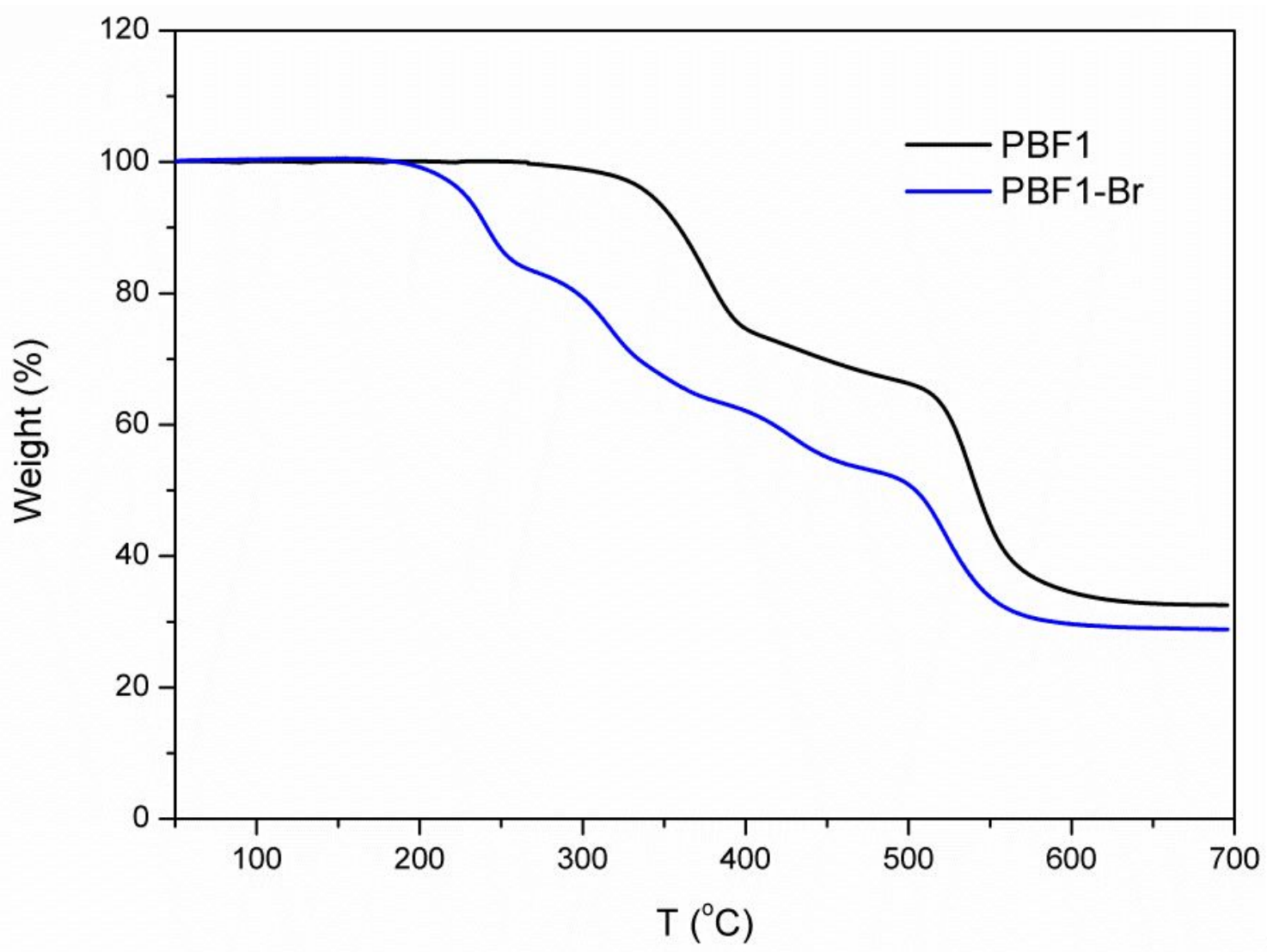

Figure S10. TGA curves of the pre-aminated PBF1 and the QA polymer PBF1-Br under $\mathrm{N}_{2}$ flow (heating rate: $10{ }^{\circ} \mathrm{C} \mathrm{min}^{-1}$ )
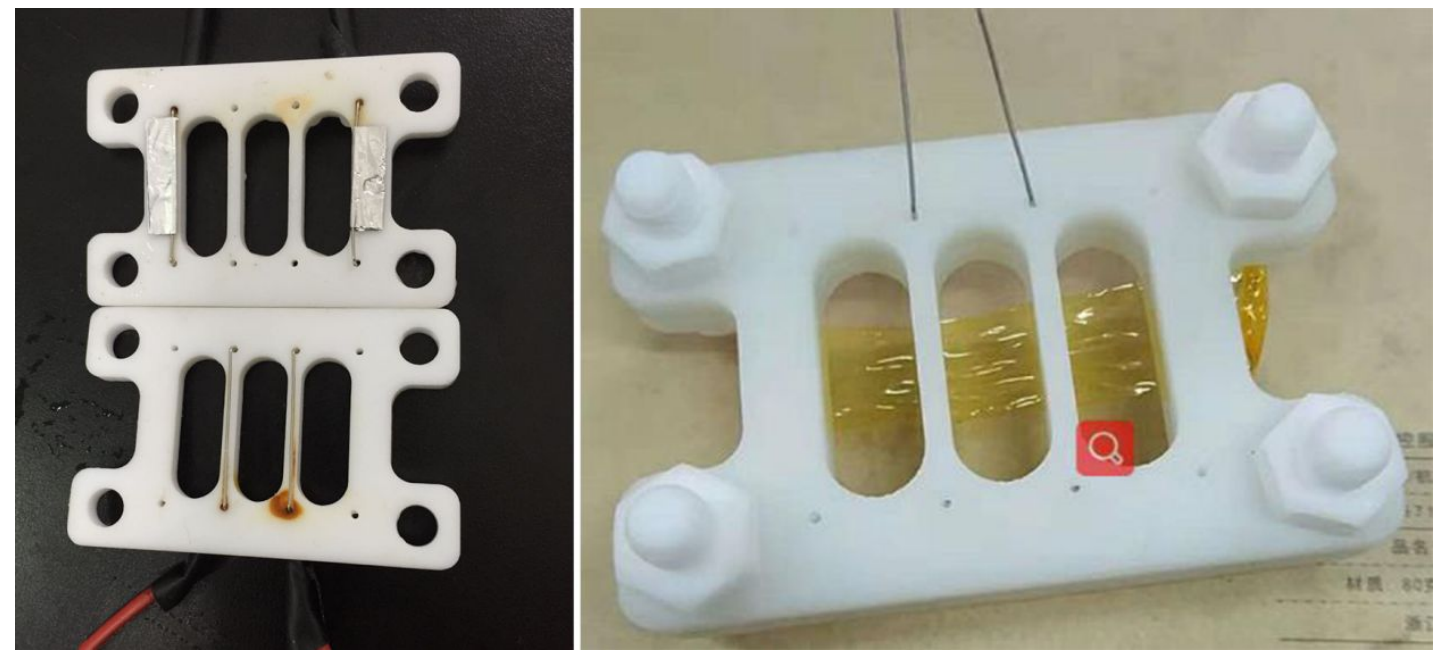

Figure S11. The photograph of the homemade 4-probe conductivity cell and the AEM sandwich between two parts of the conductivity cell for test 
Table S1. Molecular Weight Properties of Precursor Polymers

\begin{tabular}{lccc}
\hline Polymer & $\begin{array}{c}\mathrm{M}_{\mathrm{n}}{ }^{\mathrm{a}} \\
10^{4} \mathrm{~g} / \mathrm{mol}\end{array}$ & $\begin{array}{c}\mathrm{M}_{\mathrm{w}}{ }^{\mathrm{b}} \\
10^{4} \mathrm{~g} / \mathrm{mol}\end{array}$ & PDI $^{\mathrm{c}}$ \\
\hline PF & 4.7 & 9.1 & 1.93 \\
PBF1 & 6.6 & 11.2 & 1.71 \\
PBF2 & 5.4 & 8.9 & 1.64 \\
PBF0.5 & 7.6 & 12.3 & 1.62 \\
\hline
\end{tabular}

a. Number-average molecular weight.

b. Weight-average molecular weight.

c. Polydispersity index, $\mathrm{PDI}=\mathrm{M}_{\mathrm{w}} / \mathrm{M}_{\mathrm{n}}$.

Table S2. IECs of polyfluorene with different ratios of fluorene

\begin{tabular}{ccccc}
\hline Polymer & IEC & IEC & IEC & IEC $^{\text {d }}$ \\
& mequiv/g & mequiv/g & mequiv/g & mequiv/g \\
\hline PF & 2.55 & 2.53 & -- & -- \\
PBF0.5 & 1.56 & 1.57 & $1.52 \pm 0.03$ & $1.48 \pm 0.04$ \\
PBF1 & 1.94 & 1.92 & $1.89 \pm 0.04$ & $1.91 \pm 0.03$ \\
PBF2 & 2.2 & 2.19 & $2.18 \pm 0.04$ & $2.16 \pm 0.04$ \\
\hline
\end{tabular}

a. Calculated from the feeding ratios.

b. Calculated from the ${ }^{1} \mathrm{H}$ NMR (Figure S6) by the ratio of aromatic hydrogen at 7-8 ppm and the $-\mathrm{CH}_{3}$ of piperidinium at $2.95 \mathrm{ppm}$.

c. Experimental value determined by titration.

d. Experimental value determined by titration after alkaline stability test (after $1200 \mathrm{~h}$ in $1 \mathrm{M} \mathrm{NaOH}$ at $80^{\circ} \mathrm{C}$ ). 
Table S3. Conductivity and mechanical properties of PBF AEMs before and after alkaline treatment.

\begin{tabular}{ccccccc}
\hline \multirow{2}{*}{ AEMs } & OH- conductivity & \multicolumn{2}{c}{ Tensile strength } & \multicolumn{2}{c}{ Elongation at break } \\
& \multicolumn{2}{c}{ mS/cm } & \multicolumn{2}{c}{$(\mathrm{MPa})$} & & \\
\cline { 2 - 7 } & Before & After & Before & After & Before & After \\
\hline PBF0.5 & 61 & 60 & 31.5 & 32.5 & 8.9 & 8.5 \\
PBF1 & 69 & 70 & 27.6 & 27.1 & 7.0 & 6.9 \\
PBF2 & 86 & 87 & 25.2 & 26.0 & 6.4 & 6.2 \\
\hline
\end{tabular}

a. Measured in hydrated at $80^{\circ} \mathrm{C}$.

\section{REFERENCES}

1. Saikia, G.; Iyer, P. K., Facile C-H Alkylation in Water: Enabling Defect-Free Materials for Optoelectronic Devices. J. Org. Chem. 2010, 75 (8), 2714-2717.

2. Poynton, S. D.; Slade, R. C. T.; Omasta, T. J.; Mustain, W. E.; Escudero-Cid, R.; Ocón, P.; Varcoe, J. R., Preparation of Radiation-grafted Powders for Use as Anion Exchange Ionomers in Alkaline Polymer Electrolyte Fuel Cells. J. Mater. Chem. A 2014, 2 (14), 5124-5130. 